\title{
Estimating Solar Power Integration into Vietnam's Power Mix with the Combinatorial Modelling Approach
}

\author{
Aleksey V. Edelev', Nguyen Hoai ${ }^{1}{ }^{2}$, Quyen Le Luu ${ }^{2}$ \\ ${ }^{1}$ Melentiev Energy Systems Institute of Siberian Branch of the Russian Academy of Sciences, \\ Lermontov str., 130 \\ Irkutsk, Russia \\ E-mail: flower@isem.irk.ru \\ ${ }^{2}$ IES VAST, Block A9, Hoang Quoc Viet Street, \\ Cau Giay District, \\ Hanoi, Vietnam \\ E-mail:nhnam@ies.vast.vn
}

\begin{abstract}
Nowadays long-term energy system optimization models are frequently used in studies analysing the transition towards a sustainable energy system with an increased share of intermittent renewable energy sources. Highly variable and stochastic nature of renewable energy sources poses some challenges to long-term energy system optimization models due to using a low temporal resolution and neglecting the short-term dynamics. The common approach to withstand those challenges is the soft-linking of long-term energy system optimization models to a short-term operational power system models. Such approach is proposed to investigate the future Vietnam electricity market in terms of supply-demand balance and how renewable energy sources could help to improve the performance of electricity market to 2030/2035. A hybrid model consists of previously developed Vietnam energy sector model with the model of power shortage estimation of power systems. This hybrid model and appropriate reliability indexes constitute the part of system-wide constraints of combinatorial modelling framework
\end{abstract}

Keywords: Combinatorial modelling, renewable energy, long-term energy development, power system, decision support.

\section{Introduction}

Growth in renewable energy (RE), particularly wind and solar photovoltaics (PV), has increased the complexity of the power system operation. Due to the intermittent nature of RE, there are concerns over the potential operational and economic impacts of RE on the operation and development of the power system, on the transmission grid, ancillary services and the energy mix (EM). The EM is a technological structure of electricity generating units in a power system, able to provide power and energy balance [1]. The distribution grid might get overloaded due to locally connected RE sources. The transmission grid needs to deal with major imbalances between regions [2]. Also, a significant amount of conventional power plants is still needed to ensure uninterrupted electricity supply. As RE is a nearly zero marginal cost technology (and hence drop in the average electricity price), renewable energy leads to a displacement of conventional power plants in EM, which poses a threat to the security of electricity supply in the medium- to long-term [3].
The wind and solar power variability may create operational challenges for thermal plants by necessitating frequent cycling, including ramping and startup/shutdown. Large thermal plants may have technical limitations and additional costs associated with cycling. Another challenge is that wind and PV are non-synchronous and therefore cannot provide synchronous initial frequency response and high fault feed-in currents to the system [4].

Therefore capturing the economic and technical challenges related to RE large-scale penetration requires analysis of EM taking into account an access to the fuel and technical constraints on the power system operation as well as ensuring electricity supply security and power system reliability [1].

In order to integrate high levels of RE into a power system, one can use a number of modelling tools to understand the technical and economic impacts of investing in RE technologies [5]. Generally, the modelling tools most commonly used can be divided into operational power system models [6] and long-term 
energy system optimization models [7]. The power system models simulate the operation of a power system, given a certain EM, over a relatively short period, typically one year but at high temporal resolution, typically sub-hourly. The long-term energy system optimization models perform the multi-year analysis of the evolution of a system paying into attention changes in technologies and fuel prices without accounting for details of power system operation. Sometimes the long-term energy system optimization models are identified shortly as energy system models, while operational power system models as power system ones. While the two most common approaches for energy systems modelling can provide useful insights on the impact of using RE sources combining them is always complex but highly required process $[8,9]$. The development of hybrid modelling methodologies that allow combining both approaches is, therefore, crucial to design economically and technically sustainable transition pathways for electricity systems with high penetrations of RE sources [10].

There are a number of studies which integrate energy system models with short-term constrained generation dispatch in order to capture the operational implications associated with RE [9, 10]. For example, one of the recently developed models [1] allows for consideration of short-term power system operation (unit commitment and dispatch) in long-term investment planning resulting in reliable EM, which has the higher marginal cost of electricity generation but is more flexible and provides a higher level of security of supply.

The most common approach is to interlink between energy system models and power system models, with or without feedback between both models [10-12]. A power system model thus transposes short-term operational dynamics of the power system to the EM resulting from the high-level optimisation procedure of an energy system model. The two models are usually applied iteratively in order to check the operational feasibility of the investment plan. For example, in [4], a long-term generation portfolio planning model is integrated with a short-term dispatch simulation model. The wide acceptance of such hybrid framework stems from its simplicity, computational tractability and use of well-known modelling packages [13]. There are some implications of interlinking two models. Long-term investment strategies can be sub-optimal due to the optimisation of the energy system model does not take into account operational details as captured by the power system model. The overlapping but different sets of input parameters of each of these models could lead to hidden input data inconsistency [9].

Soft-linking models ensure the most accurate results regarding the EM, but it needs setting up two standalone modelling packages. Another approach is to retrieve some heuristics from a power system model and implement it in the energy system model, as demonstrated in the implementation of flexibility requirements in OSeMOSYS [9, 14] or in MESSAGE [15] energy system models. According [16] results are closer to those of a soft-linking approach while keeping a small computation burden and a low temporal resolution.

There are some investigations of the development of the Vietnamese energy system [17-23]. They exploit by optimization methods and empirical studies the issues of sustainable long-term development of the power system of Vietnam with reference to the RE potential. But they do not consider the operational and economic impacts of high-level RE integration into the power system of Vietnam.

It needs to investigate the future Vietnam electricity market in terms of supply-demand balance and how renewable energy sources could help to improve the performance of electricity market to 2030/2035. It is argued that before the liberalization of the market, Vietnam must sustain the supply in order to avoid external risks that market could be exposed.

A research on impacts of solar power integration into Vietnam power generation could answer the questions of whether it is possible to safely integrate that solar power potential and how much the total investments might cost. In this paper, the applicability of the combinatorial modelling framework [24] is considered for that research. This framework has been used to study the sustainable development of energy sector of Russia [25] and Vietnam [26] previously.

\section{Current Status and Prospect of Vietnam's energy sector}

By 2016, Vietnam's primary energy consumption was 59.2 million ton of oil equivalent (TOE), equivalent to an average annual growth rate of $3.56 \%$ in 2012-2016. According to the Ministry of Industry and Trade (MOIT), the total primary energy consumption of the system will amount to about 134.5 million TOE in 2035 , equivalent to an average annual demand growth of $4.7 \%$ in the period 2016-2035. It is noteworthy that, among energy-intensive sectors, the industry is forecasted to grow at $5.0 \%$ per year for the period 2016- 
2035, ranked second, behind the transport sector $(5.7 \%$ per year).

In this context, energy supply is increasingly dependent on coal and imported fuels. It is estimated in the [27] that energy imports will account for $37.5 \%$ of the energy mix in 2025, and 58.5\% in 2035 (Fig. 1). Therefore, the current and future energy security status of Vietnam is not guaranteed. Risks of supply-demand imbalance and a higher dependence on imported energy sources result in vulnerability to external shocks such as energy market volatility or geopolitical instability in the region and the world.

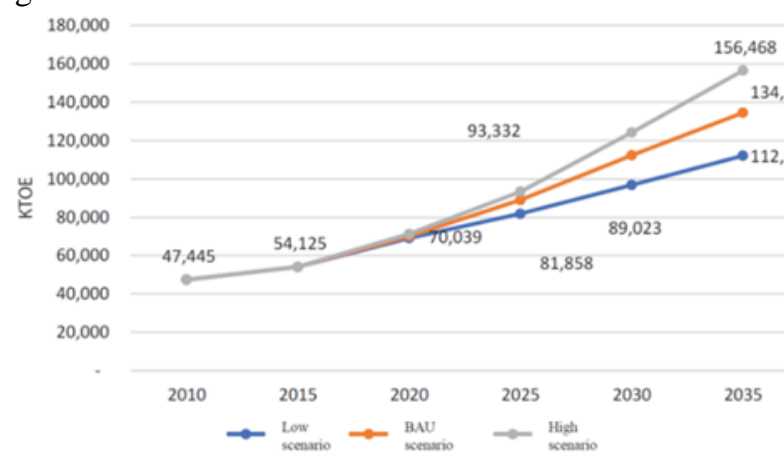

Fig. 1. Vietnam Forecast of Total Final Energy Demand to 2035.

On November 25, 2015, GVN released the National Renewable Energy Development Strategy (Decision 2068/QD-TTg), to express preferential mechanisms for RE development, including bio-energy, biogas, wind and solar energy until 2030, with a vision to 2050. In the period until 2030, Vietnam will prioritize the development of onshore wind farms. GVN will consider offshore wind farms for research and development in the post-2030 period. In addition to farm-scale development, GVN will also deploy solar power in island, border, remote areas, and areas without access to the power grid.

In order to achieve the objectives of the strategy, GVN has introduced a number of incentives such as two-way meters, preferential import tariffs, and support to the local production of RE technologies and equipment, and the development of RE markets and Power Purchase Agreement (PPA) policies. One of the most important upcoming mechanisms is the Renewable Portfolio Standard (RPS). RPS requires a minimum percentage of RE power for generators with the installed capacity of more than $1,000 \mathrm{MW}$. The minimum percentage set in the strategy is $3 \%$ by $2020,10 \%$ by 2030 , and $20 \%$ by 2050 . The minimum percentage applied for distribution companies (the proportion of RE distributed by the company) is proposed to be $5 \%$ by
$2020,10 \%$ by 2030 , and $20 \%$ by 2050 in the [28], as shown in the Table 1.

Table 1. Targets for Renewable Energy for Power Production*

\begin{tabular}{|c|c|c|c|c|}
\hline & \multicolumn{4}{|c|}{ Targets } \\
\hline $\begin{array}{c}\text { Power } \\
\text { sources }\end{array}$ & 2015 & 2020 & 2030 & 2050 \\
\hline Total & $58 \mathrm{TWh}$ & $101 \mathrm{TWh}$ & $186 \mathrm{TWh}$ & $452 \mathrm{TWh}$ \\
\hline Hydro & $56 \mathrm{TWh}$ & $90 \mathrm{TWh}$ & $96 \mathrm{TWh}$ & N/A \\
\hline Wind & $0.18 \mathrm{TWh}$ & $2.5 \mathrm{TWh}$ & $16 \mathrm{TWh}$ & $53 \mathrm{TWh}$ \\
\hline Solar & $0.01 \mathrm{TWh}$ & $\begin{array}{c}1.4 \mathrm{TWh} \\
(0.5 \% \text { of } \\
\text { the total } \\
\text { power } \\
\text { mix })\end{array}$ & $\begin{array}{l}35 \mathrm{TWh} \\
(6 \% \text { of the } \\
\text { total } \\
\text { power } \\
\text { mix) }\end{array}$ & $\begin{array}{l}210 \mathrm{TWh} \\
(20 \% \text { of the } \\
\text { total power } \\
\text { mix) }\end{array}$ \\
\hline Biomass & N/A & N/A & N/A & N/A \\
\hline Biogas & $\begin{array}{c}4 \text { million } \\
\text { m3 }\end{array}$ & $\begin{array}{c}8 \text { million } \\
\text { m3 }\end{array}$ & $\begin{array}{c}60 \text { million } \\
\text { m3 }\end{array}$ & $\begin{array}{c}100 \text { million } \\
\text { m3 }\end{array}$ \\
\hline
\end{tabular}

\section{Combinatorial modelling framework}

There are two well-known approaches to the analysis of energy development options. The first "designers" approach is based on a detailed analysis of a small number (usually 3-4) of considered options. The disadvantages of this approach are the incompleteness of the possible options set, the inability to fully consider the uncertainty of the development conditions and the low adaptability of the selected options to possible condition changes in the future. The second "economicmathematical" approach is to construct a mathematical model as a mathematical problem of linear programming usually. In that approach, great difficulties arise due to the non-linear nature of many dependencies, discreteness of energy development options, the necessity to use mathematical tools that do not come to the classical systems of equations and inequalities.

The combinatorial modelling framework unites the advantages of two above-mentioned approaches.

The basis of combinatorial modelling is the representation of the system's objects development in the form of a directed graph. Nodes characterize the state of objects at particular moments of time $t=1, \ldots, T$, where $T$ is the number of time points to be allocated. Arcs are possible transitions from one state to another. All the probable ways of development of each object of the simulated system start from a single initial state at time $t=1$.

\footnotetext{
Compiled from Decision 2068/QD-TTg (2015) issued by Vietnamese Prime Minister
} 
The whole system development graph that contains the possible system states and transitions is formed by considering various combinations of states of objects at the same moments of time and various combinations of possible transitions from one state to another between the neighbour moments of time. The term "combinatorial modelling" is used because of the combinatorial rules describe the linkage between object development graphs and a system development graph. Objects are considered as structural units of a modelled system. They can be enterprises of energy sector or sets of enterprises of the same type, consumers of energy resources or categories of consumers. The depth and comprehensiveness of the system decomposition depend on a solving task and the aggregation degree of available data. Within the combinatorial modelling framework, the union of objects can be carried out in a natural way. The collection of several objects under given study can be united into a single object when considering the problem of a higher level.

The graph of admissible system development trajectories is separated from the constructed graph of possible system development as a result of the following operations:

(i) Removal of the states and transitions which violate system-wide constraints;

(ii) Removal of the states and transitions which violate the conditions of the development dynamics.

A suboptimal trajectory is a path of the system development, in which the used criterion value differs from its optimal value by not more than a predetermined value. Optimal and suboptimal trajectories of system development are established by the dynamic programming methods [29].

The combinatorial modelling technique can help to choose the proper development directions for a system considering the system development problem in the one-criterion formulation and in the deterministic conditions. The ability to obtain the full set of suboptimal trajectories is important as a way to overcome uncertainty in the initial data.

The combinatorial modelling framework allows:

- To take into account explicitly the discreteness of options for the system objects development,

- To take into account explicitly the multi-stage character of the decision-making process,

- To use other models to assess a system state validity,

- To determine the entire set of suboptimal system development paths in deterministic conditions and under uncertainty conditions.

\section{The proposed approach to investigate impacts of solar power integration into Vietnam power generation}

The Vietnam energy sector model [30] was developed from 2011 to 2015 during the joint research conducted by the Melentiev Energy Systems Institute of Siberian Branch of the Russian Academy of Science (ESI SB RAS) and the Institute of Energy Science of Vietnam Academy of Science and Technology (IES VAST).

The core idea is a soft-linking the developed Vietnam energy sector model with the model of power shortage estimation of power systems [31]. The first model implements traditional long-term capacity planning while the second one captures the load dispatch in the power system. This linkage allows the access to the fuel and technical constraints on the Vietnamese power system operation as well as accounting the requirements of electricity supply security and power system reliability.

This hybrid framework and appropriate reliability indexes described below constitute the part of systemwide constraints to check the validity of possible Vietnam's energy system state.

The general methodology of the combinatorial modelling framework and its method's application are described in [24-26].

\subsection{The model of power shortage estimation of power systems}

Let's consider a scheme of the power system which contains $n$ nodes and set of system links. Let $N$ is number of simulated states of the electric power system. Each system state is characterized of a set of random values such as of available generating capacity $\bar{x}_{i}^{k}$, the value of load $\bar{y}_{i}^{k}$ in node $i$, power line capacity $\bar{z}_{i j}^{k}$ between nodes $i$ and $j, i=1 \ldots n, j=1 \ldots n, i \neq j, k=1 \ldots N$.

Let $x_{i}$ is the power used at the node $i, y_{i}$ is the power served at the node $i, z_{i j}$ is power flow from the node $i$ to the node $j, i=1 \ldots n, j=1 \ldots n, i \neq j$. The following problem was proposed in [31] for power shortage estimation of system state with the number $k, k=1 \ldots N$.

$$
\sum_{i=1}^{n} y_{i} \rightarrow \max
$$

subject to constraints

$$
\begin{gathered}
x_{i}-y_{i}+\sum_{j=1}^{n}\left(1-a_{j i} z_{j i}\right) z_{j i}-\sum_{j=1}^{n} z_{i j}=0, i=1, \ldots, n, \\
0 \leq y_{i} \leq \bar{y}_{i}^{k}, i=1, \ldots, n, \\
0 \leq x_{i} \leq \bar{x}_{i}^{k}, i=1, \ldots, n,
\end{gathered}
$$




$$
0 \leq z_{i j} \leq \bar{z}_{i j}^{k}, i=1, \ldots, n, j=1, \ldots, n, i \neq j .
$$

Here $a_{i j}$ are given positive coefficients of specific power losses during electric energy transfer the node $i$ to the node $j, i=1 \ldots n, j=1 \ldots n, i \neq j$.

The uniqueness of the optimal solution of the problem (1)-(5) by variables $y_{i}, i=1 \ldots n$, follows from proved theorems in [31]. The uniqueness of meanings of variables $y_{i}, i=1 \ldots n$, in optimal solution of the problem (1)-(5) for all numbers $k$ guaranties the unambiguity of computed reliability indexes.

\subsection{Computation of reliability indexes}

The modelling of random values is realized by next way. At first, the number of working generators of every type is found. At the next step, the value of maximal generation is defined on the active generators. Additionally, a random value of generated power is modelled for equipment with random generation. The procedure of random values modelling is detailed described in [32].

Adequacy analyses are based on indexes which are computed as a result of many times estimation of random states of the power system. There are the most utilized indexes such as the probability of non-deficit system operation, mathematical expectation of power shortage and electricity supply coefficient. The indexes Loss of Load Expectation and Loss of Load Hours [33] are analogues of discussed indexes. For increasing quality of adequacy analysis, it is possible to use special indexes which are taken into account of the peculiarities of the researched power system, for example, mathematical expectation of power generation on wind farms.

\section{Conclusion}

Nowadays energy system models are frequently used in studies analysing the transition towards a sustainable energy system with an increased share of intermittent RE. The use of either wind generator or solar PV is economically feasible in rural villages and remote areas of Vietnam [21]. These technologies are clean and can be constructed even at the remotest corners of Vietnam within a short period of time.

However, highly variable and stochastic nature of RE sources poses some challenges to energy system models due to using a low temporal resolution and neglecting the short-term dynamics. It leads to suboptimal investments, a considerable operational costs underestimation. Finally, both the impact of the temporal resolution and the inclusion of technical detail are increased with the share of RE sources in the power system.

The common approach to withstand those challenges is the soft-linking of an energy system model to a short-term dispatch simulation model. The main advantages of such hybrid framework are simplicity, computational tractability and use of well-known modelling packages. One of the drawbacks is a risk of hidden input data inconsistency because both models use overlapping but different sets of input parameters.

Such hybrid approach is proposed to investigate the future Vietnam electricity market in terms of supplydemand balance and how renewable energy sources could help to improve the performance of electricity market to 2030/2035.

\section{Acknowledgements}

The authors especially thank the IES VAST for providing fund and creating favour in data collection during the implementation of the study.

This paper is developed as a subsidiary component of the study "Research on methodology and software to assess the power system reliability with consideration of renewable energy and other fuels for Vietnam power plants" Code: VAST.07.04/16-17. Also, the work was carried out within the framework of the scientific project III.17.5 of the program of fundamental research of the SB RAS, No. AAAA-A17-117030310451-0.

\section{References}

1. M. Wierzbowski, W. Lyzwa and I. Musial, MILP model for long-term energy mix planning with consideration of power system reserves, Applied Energy 169 (2016) 93111.

2. C. De Jonghe, E. Delarue, R. Belmans and W. D'haeseleer, Determining optimal electricity technology mix with high level of wind power penetration, Applied Energy 88(6) (2011) 2231-2238.

3. A. Coester, M. W. Hofkes and E. Papyrakis, An optimal mix of conventional power systems in the presence of renewable energy: A new design for the German electricity market, Energy Policy 116 (2018) 312-322.

4. P. Vithayasrichareon, J. Riesz and I. MacGill, Operational flexibility of future generation portfolios with high renewables, Applied Energy 206 (2017) 32-41.

5. J. Després, N. Hadjsaid, P. Criqui and I. Noirot, Modelling the impacts of variable renewable sources on the power sector: Reconsidering the typology of energy modelling tools, Energy 80 (2015) 486-495.

6. D. Connolly, H. Lund, B. V. Mathiesen and M. Leahy, A review of computer tools for analysing the integration of renewable energy into various energy systems, Applied energy 87(4) (2010) 1059-1082. 
7. M. Gargiulo and B. O. Gallachóir, Long-term energy models: Principles, characteristics, focus, and limitations, Wiley Interdisciplinary Reviews: Energy and Environment 2(2) (2013) 158-177.

8. J. P. Deane, A. Chiodi, M. Gargiulo and B. P. Ó. Gallachóir, Soft-linking of a power systems model to an energy systems model, Energy 42(1) (2012) 303-312.

9. M. Welsch, P. Deane, M. Howells, B. Ó. Gallachóir, F. Rogan, M. Bazilian and H. H. Rogner, Incorporating flexibility requirements into long-term energy system models-A case study on high levels of renewable electricity penetration in Ireland, Applied Energy 135 (2014) 600-615.

10. A. Pina, C. A. Silva and P. Ferrão, High-resolution modeling framework for planning electricity systems with high penetration of renewables, Applied Energy 112 (2013) 215-223.

11. S. Collins, J. P. Deane, K. Poncelet, E. Panos, R. C. Pietzcker, E. Delarue and B. P. Ó. Gallachóir, Integrating short term variations of the power system into integrated energy system models: A methodological review, Renewable and Sustainable Energy Reviews 76 (2017) 839-856.

12. Q. Zhang, B. C. Mclellan, T. Tezuka and K. N. Ishihara, An integrated model for long-term power generation planning toward future smart electricity systems, Applied Energy 112 (2013) 1424-1437.

13. V. Oree, S. Z. S. Hassen and P. J. Fleming, Generation expansion planning optimisation with renewable energy integration: A review, Renewable and Sustainable Energy Reviews 69 (2017) 790-803.

14. M. Welsch, M. Howells, M. R. Hesamzadeh, B. Ó Gallachóir, P. Deane, N. Strachan, H. Rogner et al., Supporting security and adequacy in future energy systems: The need to enhance long-term energy system models to better treat issues related to variability, International Journal of Energy Research, 39(3) (2015) 377-396.

15. P. Sullivan, V. Krey and K. Riahi, Impacts of considering electric sector variability and reliability in the MESSAGE model, Energy Strategy Reviews 1(3) (2013) 157-163.

16. M. Welsch, M. D. Mentis and M. Howells, Long-term energy systems planning: accounting for short-term variability and flexibility, in Renewable Energy Integration, ed. L. Jones (Academic Press, 2014) pp. 215-225

17. K. Q. Nguyen, Wind energy in Vietnam: Resource assessment, development status and future implications. Energy Policy, 35(2) (2007) 1405-1413.

18. N. T. Nguyen and M. Ha-Duong, Economic potential of renewable energy in Vietnam's power sector, Energy Policy, 37(5) (2009) 1601-1613.

19. N. T. Nguyen, Programming Sustainable Development in a Developing Country: A Social Optimization of the
Vietnamese Power Sector. (PhD Thesis. EHESS, Paris, France, 2011)

20. P.K. Toan, N.M. Bao and N.H. Dieu, Energy supply, demand, and policy in Viet Nam, with future projections, Energy Policy 39(11) (2011) 6814-6826.

21. Q. K. Nguyen, Long term optimization of energy supply and demand in Vietnam with special reference to the potential of renewable energy (Doctoral dissertation, Universität, Oldenburg, 2005).

22. K. Q. Nguyen, Alternatives to grid extension for rural electrification: Decentralized renewable energy technologies in Vietnam, Energy Policy 35(4) (2007) 2579-2589.

23. A. Kies, B. Schyska, D. T. Viet, L. von Bremen, D. Heinemann and S. Schramm, Large-Scale Integration of Renewable Power Sources into the Vietnamese Power System. Energy Procedia, 125 (2017) 207-213.

24. A. Edelev and I. Sidorov, Combinatorial Modeling Approach to Find Rational Ways of Energy Development with Regard to Energy Security Requirements, in International Conference on Numerical Analysis and Its Applications (Springer, Cham, 2016), pp. 317-324.

25. S. M. Senderov and A. V. Edelev, Technology to Ensure Energy Security in Development of Russia's Energy Strategy, Energy Systems Research 1(1) (2018) 35-43.

26. A. V. Edelev, V. I. Zorkaltsev, Doan Binh Duong, Nguyen Hoai Nam, The Combinatorial Modelling of Vietnam Energy Development, Energy Systems Research 1(1) (2018) 67-73.

27. Vietnam Energy Outlook Report, MOIT (2017).

28. Vietnam National Renewable Energy Development Strategy (2017)

29. R. Bellman, The theory of dynamic programming, Bulletin of the American Mathematical Society, 60(6) (1954) 503-515.

30. Alexei V. Edelev, Nguyen Quang Ninh, Nguyen Van The, Tran Viet Hung, Le Tat Tu, Doan Binh Duong, Nguyen Hoai Nam, Developing "Corrective" software: 3region model, in Proc. International Conference Green Energy and Development, (Hanoi, Vietnam, 2012), pp. 41-52.

31. V. I. Zorkaltsev and S. M. Perzhabinsky, Models of power shortage estimation of electric power system, Journal of Applied and Industrial Mathematics, 12(1) (2012) 34-43. In Rus.

32. D. S. Krupenev and S. M. Perzhabinsky, Assessment of the reliability of electric power systems with wind power plants, in Proceedings of the Russian Academy of Sciences. Power Engineering, 2 (2017) 39-47. In Rus.

33. Y. Y. Chukreev, Comparison of domestic and foreign probabilistic indicators of balance reliability of electric power systems, in Proceedings of the Russian Academy of Sciences. Power Engineering, 6 (2012) 27-38. In Rus. 